\title{
Effect of Thermomechanical Processing on the Microstructure and Mechanical Properties of Low Carbon Steel
}

\author{
Shao zhenyao ${ }^{a}$, Wang zhichao ${ }^{b}$, Li Zhuang ${ }^{\mathrm{c} *}$, Wang Shuai ${ }^{\mathrm{d}}$, Wang Jijie
}

School of Materials Science and Engineering, Shenyang Aerospace University, Shenyang 110136, Liaoning, China

ashaozhenyao1991@163.com, b1419046187@qq.com, 'Lizhuang20047@163.com, d65948813@qq.com, ewangjijie@syiae.edu.cn

* Lizhuang20047@163.com

Keywords: Low carbon steel; fast cooling; the mechanical properties; standard requirement.

Abstract. Effect of thermomechanical processing on the mechanical properties of low carbon cold forging steel was investigated for different processing parameters on a laboratory hot rolling mill. Fast cooling is a key factor in thermomechanical processing. The mechanical properties of specimen 2 which was fast cooled from high finish rolling temperature exceed the standard requirement of ML30 Steel. This is attributed to the presence of substantial amounts of pearlite. Finish rolling temperature also affects the mechanical properties of steels. Low temperature rolling results in the ferrite-grain refinement. The mechanical properties of the specimen 4 exceed the standard requirement of ML25 Steel.

\section{Introduction}

Cold-heading-quality bars are mainly used for connecting parts such as bolts, nuts, and threads in many industrial areas such as automobiles, machineries, electronics, and constructions [1]. Generally, cold forging materials of high-strength class have been made of medium-carbon steel. However, the high carbon content is to bring about a profound decrease in the cold formability of steels $[2,3]$. It is necessary to use low carbon steel in order to obtain high deformability during cold forging processes. On the other hand, The search for lower production costs is the basic reason for implementing economical technologies for products made of constructional steels using methods of thermomechanical treatment [4].

Thermomechanical processing can improve the microstructures and mechanical properties of low carbon steels [5-7]. The control of rolling temperature at the beginning of and during deformation is critical to producing a uniform region of ultrafine equiaxed ferrite $[8,9]$. Low carbon steel with controlled rolling and cooling process can offer several performance characteristics which are superior to the conventional thermal treated medium-carbon cold forging steel [7]. It is an ideal process to eliminate the need of thermal treatment for cold forging steel production because employing thermomechanical controlled processing (TMCP) can meet the demands of raw material [10-12].

In this paper, low carbon steel was investigated to better understand of the TMCP. Four finish rolling temperatures of this steel were applied by means of a laboratory hot rolling mill. The microstructures were observed to discuss the mechanism for enhancing the grade of cold forging steel product.

\section{Experimental}

An ingot was laboratory melted in a vacuum induction furnace, and it was then cast and forged into eight pieces of $80 \times 80 \times 30 \mathrm{~mm}$ thick slabs. The chemical composition and standard requirements (GB6478-86) [13] of cold forging steel is shown in Table 1.

The specimens were heated up to $1150^{\circ} \mathrm{C}$ and held there for $1 \mathrm{~h}$ to obtain single austenite microstructure. The specimens were then rolled at a start rolling temperature of $1000^{\circ} \mathrm{C}$ down to a thickness of $4 \mathrm{~mm}$. Four slabs were rolled at intervals during two passes of deformation in hot rolling to attain various finish rolling temperatures. After finished rolling, four slabs were water cooled at 
$12.63 \sim 37.50^{\circ} \mathrm{C} / \mathrm{s}$ on a runout table to $550^{\circ} \mathrm{C}$ (Absolute error of final cooling temperature was limited to $20 \sim 30^{\circ} \mathrm{C}$ ), and then were air cooled to room temperature. The parameters of thermomechanical processing schedule are shown in Table 2.

Table 1. Chemical composition of the cold forging steel \%

\begin{tabular}{cccc}
\hline steel & $\mathrm{C}$ & $\mathrm{Si}$ & $\mathrm{Mn}$ \\
\hline The investigated & 0.186 & 0.171 & 0.437 \\
steel & & & \\
ML20 Steel & $0.17 \sim 0.24$ & $\leq 0.07$ & $0.20 \sim 0.50$ \\
ML25 Steel & $0.22 \sim 0.30$ & $\leq 0.20$ & $0.30 \sim 0.60$ \\
ML30 Steel & $0.27 \sim 0.35$ & $\leq 0.20$ & $0.30 \sim 0.60$ \\
\hline
\end{tabular}

Table 2. Measrued technical parameters during TMCP

\begin{tabular}{|c|c|c|c|}
\hline Specimen no & $\begin{array}{l}\text { Cooling rates } \\
\text { from the } \\
\text { finish rolling } \\
\text { temp. }{ }^{\circ} \mathrm{C} / \mathrm{s} \\
\end{array}$ & $\begin{array}{l}\text { Start } \\
\text { rolling } \\
\text { temp. } \\
/{ }^{\circ} \mathrm{C} \\
\end{array}$ & $\begin{array}{l}\text { Finish } \\
\text { rolling } \\
\text { temp. } /{ }^{\circ} \mathrm{C}\end{array}$ \\
\hline 1 & 39.14 & \multirow{4}{*}{1000} & 950 \\
\hline 2 & 38.28 & & 900 \\
\hline 3 & 37.66 & & 850 \\
\hline 4 & 29.08 & & 800 \\
\hline
\end{tabular}

Four specimens of transverse sections from the rolling direction were examined by light optical microscopy (LOM) and scanning electron microscopy (SEM). The microstructure was revealed using $4 \%$ Nital. The pearlite fractions were assessed with image analysis software of Leica. Tensile tests were conducted in an INSTRON 4206 machine, and all tests were performed at room temperature.

\section{Experimental Results}

\section{Microstructures}

Fig. 1 and 2 show representative microstructures formed as a result of various finish rolling temperatures schedules. The pearlite morphologies and the ferrite grain sizes of the specimens at various TMCP are quite different, despite the microstructures of all specimens after hot rolling consist of ferrite and pearlite. When the finish rolling temperature was $900^{\circ} \mathrm{C}$, there are substantial amounts of pearlite at fast cooling rate of $38.28^{\circ} \mathrm{C} / \mathrm{s}$ (Fig. 1(b) and 2(b)). While the same substantial amounts of pearlite at the lowest cooling rate of $29.08^{\circ} \mathrm{C} / \mathrm{s}$ were observed when the finish rolling temperature was $800^{\circ} \mathrm{C}$. At the same time, Widmanstätten in specimens 4 was found, despite this widmanstätten morphology is not serious (Fig. 1(d) and 2(d)). The content of pearlite decreased considerably at the cooling rates of $39.14^{\circ} \mathrm{C} / \mathrm{s}$ and $37.66^{\circ} \mathrm{C} / \mathrm{s}$ when the finish rolling temperature were $950^{\circ} \mathrm{C}$ and $850^{\circ} \mathrm{C}$, respectively (Fig. 1(a) and 2(c)).

The refinement of the ferrite grains is remarkable at the fastest cooling rate of $38.28^{\circ} \mathrm{C} / \mathrm{s}$ when the finish rolling temperature was $950^{\circ} \mathrm{C}$ (Fig. 1(a)). The ferrite grain sizes of specimen 1 and 3 are $36.12 \mu \mathrm{m}$ and $38.47 \mu \mathrm{m}$, respectively. And the ferrite grains are coarse, despite it is difficult to measure the ferrite grain sizes of specimens at the finish rolling temperature of $900^{\circ} \mathrm{C}$ and $800^{\circ} \mathrm{C}$ for the presence of pearlite and widmanstätten. However, the ferrite grain sizes of specimen 2 and 4 are still $55.54 \mu \mathrm{m}$ and $53.35 \mu \mathrm{m}$, respectively (Fig. 1 (b)(d)). This is because fast cooling refines the ferrite grain size considerably.

The pearlite fractions and ferrite grain sizes of the specimens at various finish rolling temperatures are shown in Fig.3.

Specimens were observed under SEM in detail. The results are shown in Fig. 4. The pearlite morphology and the ferrite grain size of the specimens are consistent with the optical metallography. In 
Fig. 4, Interlamellar spacing in pearlite colony of specimen 2 and 4 are almost the same. And it is refined to a certain degree due to relatively fast cooling rate of $39.14^{\circ} \mathrm{C} / \mathrm{s}$ (Fig. 4(a)).

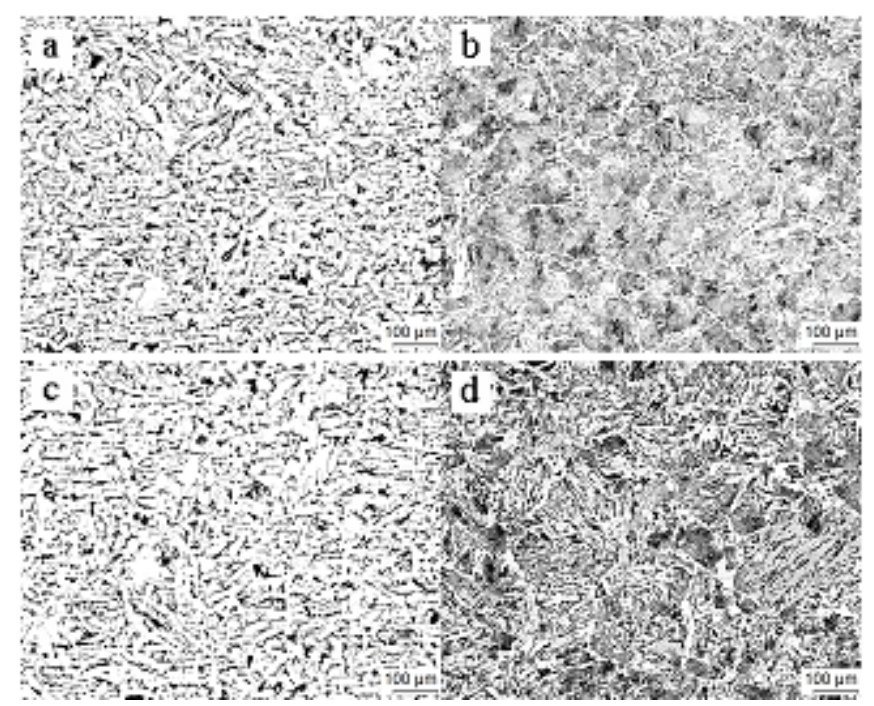

(a) Specimen 1; (b) Specimen 2; (c) Specimen 3; (d) Specimen 4

Fig.1 Optical micrographs of specimens

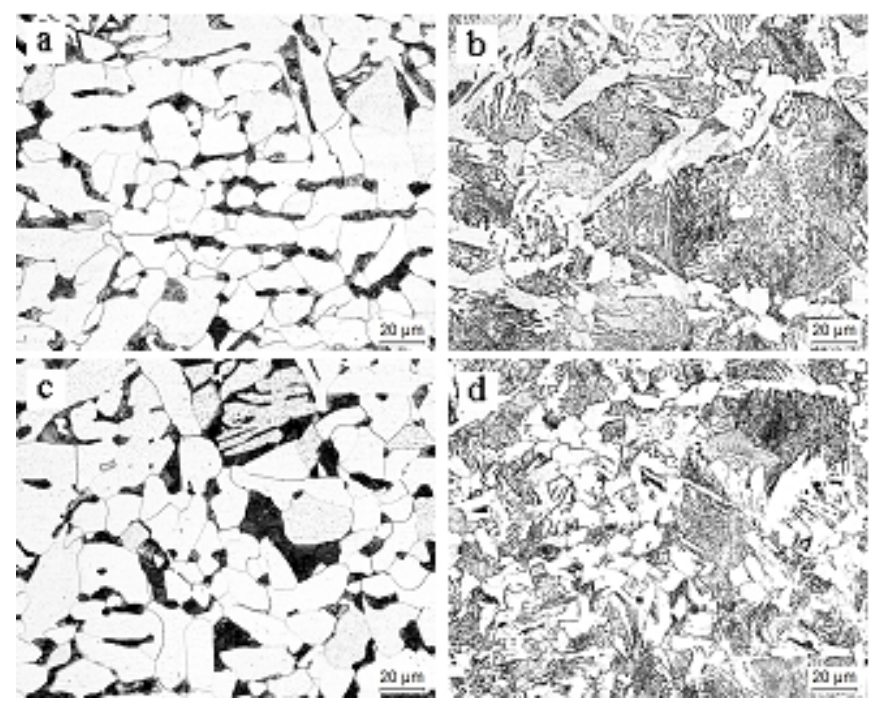

(a) Specimen 1; (b) Specimen 2; (c) Specimen 3; (d) Specimen 4

Fig.2 Optical micrographs of specimens

\section{Mechanical properties}

Fig. 5 shows ultimate tensile strength (UTS), yield strength (YS) and total elongation (TEL) of the specimens as above at various TMCP. The controlled hot rolling procedure accompanied by the cooling of the specimens by means of an accelerated cooling procedure reached ameliorative properties to cold forging steel grade.

The standard requirements of the cold forging steel are shown in Table 3. 


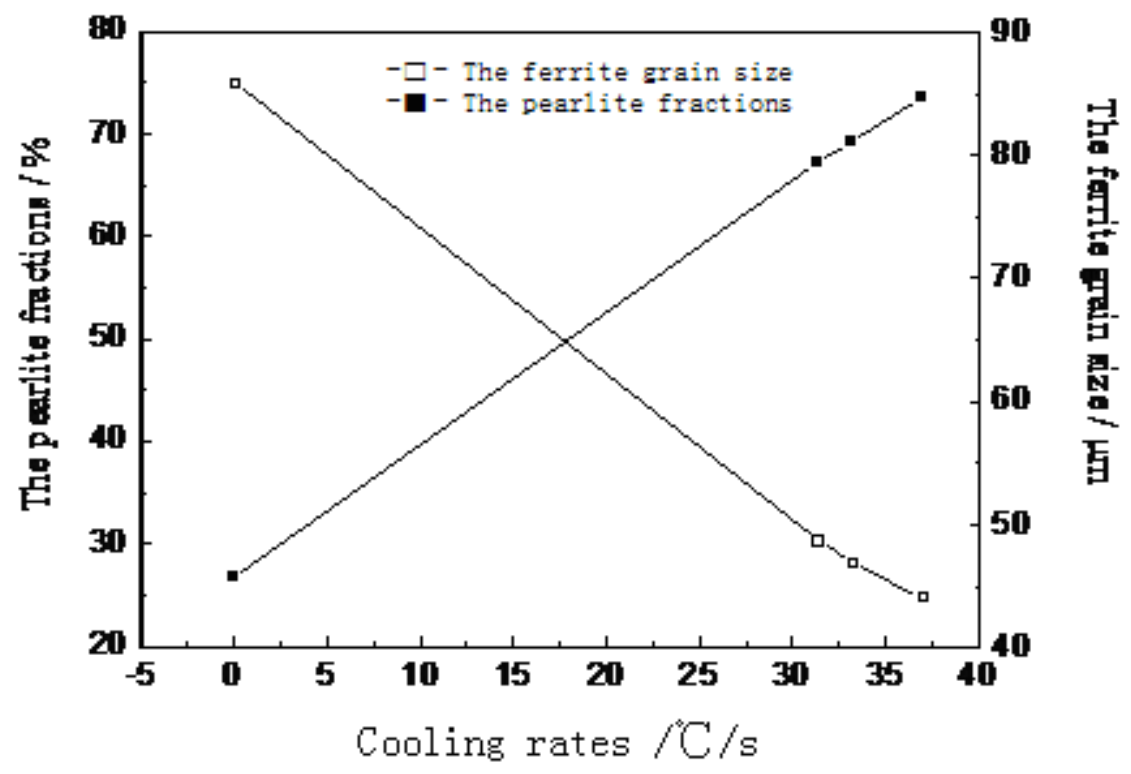

Fig. 3 The pearlite fractions and ferrite grain sizes of the specimens at various finish rolling temperatures
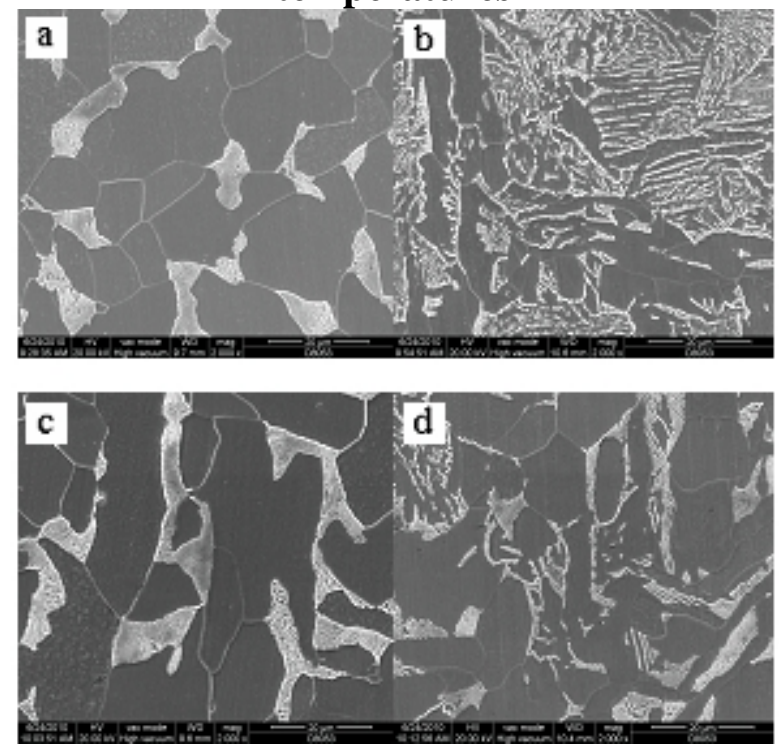

(a) Specimen 1; (b) Specimen 2; (c) Specimen 3; (d) Specimen 4

Fig.4 SEM micrographs of specimens

Table 3. The standard requirements of the cold forging steel

\begin{tabular}{lccc}
\hline $\begin{array}{l}\text { The standard } \\
\text { requirements }\end{array}$ & $\begin{array}{l}R_{\mathrm{m}} / \mathrm{M} \\
\mathrm{Pa}\end{array}$ & $\begin{array}{c}R_{\mathrm{eL}} / \mathrm{M} \\
\mathrm{Pa}\end{array}$ & $A_{50} / \%$ \\
\hline ML20 Steel & 412 & 245 & 25 \\
\hline ML25 Steel & 451 & 275 & 23 \\
\hline ML30 Steel & 490 & 294 & 21 \\
\hline
\end{tabular}

The specimen 2 shows the highest UTS (520MPa). This means that the mechanical properties of specimen 2 which were conducted through TMCP are higher than those of the standard requirements of ML30. The specimens 3 and 4 exceed the standard requirement of ML25 Steel due to low temperature $\left(850^{\circ} \mathrm{C}\right.$ and $\left.820^{\circ} \mathrm{C}\right)$ rolling. As noted in Fig. 5, total elongation (TEL) of the specimens 1 and 3 reach the highest value (33\% and 34\%, respectively), despite the mechanical properties of specimen 1 reaches only the standard requirement of ML20 Steel. 


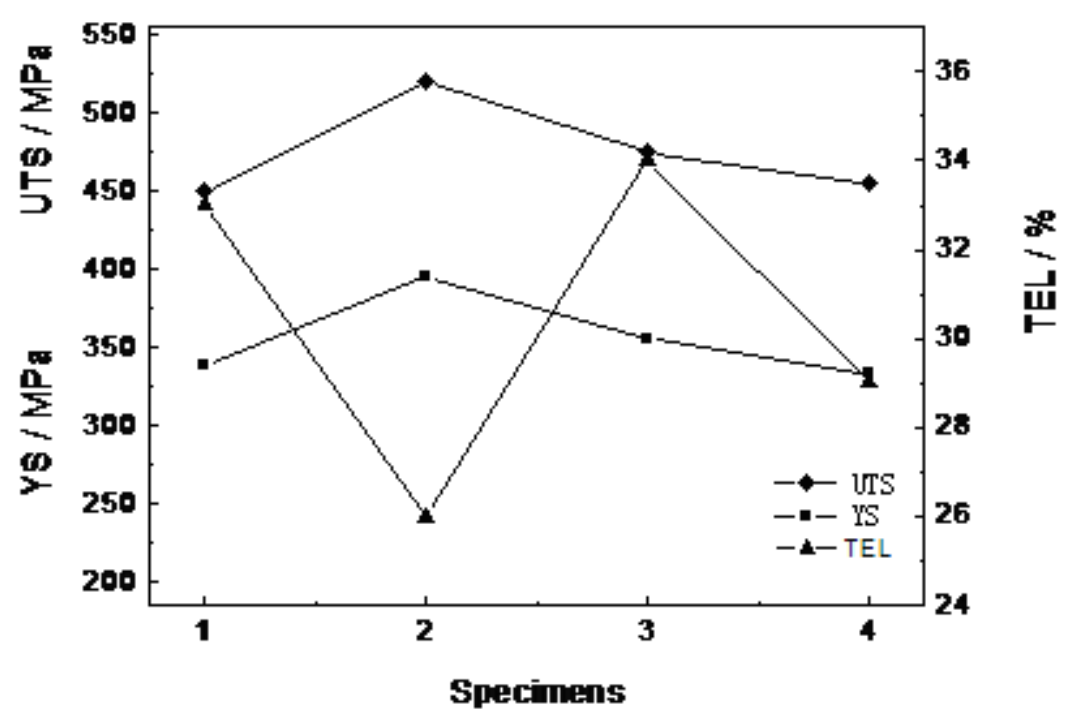

Fig.5 Mechanical properties of specimens

\section{Discussion}

TMCP was performed on a runout table for four slabs. Low carbon steels have various microstructures according to the variation of rolling and cooling conditions [14]. Fast cooling after the finished rolling suppresses recovery and recrystallization during relaxation after the deformation, which results in refined the austenite grains. Fast cooling would help to keep more dislocations introduced by deformation, remaining after cooling ${ }^{[9]}$. As a result, the strength was enhanced due to TMCP.

Fast cooling is a key factor in thermomechanical processing. Fast cooling also results in the ferrite-grain refinement. The finer ferrite grain size $(36.12 \mu \mathrm{m}$ and $38.47 \mu \mathrm{m})$ is obtained for specimens 1 and 3 due to fast cooling. Fast cooling could suppress the austenite-to-ferrite transformation during the cooling due to the less time for the diffusional transformation, and finally refine the ferrite grains. However, the contribution of the grain refinement to the mechanical properties of the steel is less than the effect of fast cooling. As was mentioned previously, finish rolling temperature of specimen 2 was $900^{\circ} \mathrm{C}$, and its mechanical properties exceed the standard requirement of ML30 Steel. The specimen at high finish rolling temperature exhibits very good mechanical properties due to fast cooling.

The amounts of pearlite had a more pronounced effect on the mechanical behavior than refinement of the microstructure. Fast cooling rates result in the presence of substantial amounts of pearlite for the specimens 2 and 4 . This is one important reason for enhancing the grade of cold forging steel product. In general, widmanstätten morphology results in poor mechanical properties of the specimen 4 .

Relative a small quantity of pearlite, it results in the mechanical properties of specimen 4 exceeds only the standard requirements of ML25 Steel.

Finish rolling temperature affects the mechanical properties of steels. Deformation bands formed during the simulated intercritical rolling divided the austenite grains into several parts. The deformation bends produced by large reduction in non-recrystallization temperature region of austenite acted as nucleation sites for ferrite formation and finally refine the ferrite grains. Specimen 4 was water cooled after low temperature rolling $\left(800^{\circ} \mathrm{C}\right)$, it resulted in a refined of the ferrite grain size. Despite the specimen 4 was at fast cooled at a relatively low rate of $29.08^{\circ} \mathrm{C} / \mathrm{s}$, the mechanical properties of specimen 4 exceed standard requirements of ML25 Steel despite at water cooling

\section{Conclusions}

(1) TMCP affects the mechanical properties of steels. Low carbon steels have various microstructures according to the variation of thermomechanical processing. The strength was enhanced due to TMCP. 
(2) Fast cooling is a key factor in thermomechanical processing. The mechanical properties of specimen 2 which was fast cooled from high finish rolling temperature exceed the standard requirement of ML30 Steel.

(3) Fast cooling rates result in the presence of substantial amounts of pearlite for the specimens 2 and 4. This is one important reason for enhancing the grade of cold forging steel product.

(4) Finish rolling temperature also affects the mechanical properties of steels. Low temperature rolling results in the ferrite-grain refinement. However, the contribution of the grain refinement to the mechanical properties of the steel is less than the effect of fast cooling. The specimen 4 only exceeds the standard requirement of ML25 Steel

\section{Acknowledgement}

This work was supported by the National Natural Science Foundation of China (No.50334010), the Shenyang City Application Basic Research Project (F13-316-1-15) and Undergraduate Innovation Project of Shenyang Aerospace University (DX508402).

\section{References}

[1] K. Hyunmin, K. Minju, B.C.M. Kim, H. Seop, L. Sunghak, Anisotropy of dynamic compressive properties of non-heat-treating cold-heading-quality steel bars, Metall. Mater. Trans. A. 45 (2014) 1294-1305.

[2] Z. Li, D.Wu, X.M. Zhao, H.H. Yu, L. Luo, Influence of Rolling and Cooling Conditions on the Mechanical Properties of Low Carbon Cold Forging Steel, Metall. Res. Technol.. 112 (2015) 204-216. [3] R. Kohlmann, M. Kruse, M. Meyer, Optimization of material properties for bars and wire rod. Metallurgical Plant and Technology International. 23 (2000): 56.

[4] M. Opiela, Effect of thermomechanical processing on the microstructure and mechanical properties of Nb-Ti-V Microalloyed, Journal of Materials Engineering and Performance. 23 (2014) 3379-3388.

[5] X.H Xue, Y.Y Shan, L Zheng, Microstructural characteristic of low carbon microalloyed steels produced by thermo-mechanical controlled process. Mater. Sci. Eng., A. 438-440 S1(2006): 285-287 [6] Y. Liu, F. Zhu, Y. Li, Effect of TMCP parameters on the microstructure and properties of an nb-ti microalloyed steel, ISIJ Int. 45 (2005): 851-857.

[7] Z. Li, D. Wu, Influence of hot rolling conditions on the mechanical properties of hot rolled TRIP steel, Journal of Wuhan University of Technology-Mater. 23 (2008): 74-79.

[8] R.Archana, S.D. Vinoo, L. Harish, M.B. Abhishek, G.V. Ramana, R. Madhusudana, R. Sah, S. Manjini, Grain refinement of C-Mn steel through thermo-mechanical processing, Journal of Engineering, Design and Technology. 13 (2015) 282-297.

[9] M.R. Hickson, P.J. Hurley, R.K. Gibbs, The production of ultrafine ferrite in low-carbon steel by strain-induced transformation, Metall Trans. 33A (2002) 1019-1026.

[10] Y.J. Zhang, S.L. Chen, H. Dong, Development and application of non-quenched and tempered steel for auto forging components in China, Iron \& Steel. 18(2011) 735.

[11] Z. Li, D. Wu, Study of the high strength and low yield ratio cold forging steel, Mater. Sci. Eng., A. $452-453$ (2007) 142.

[12] S.H. Su, W.J. Hui, T. R. Yu, On-line softening of medium carbon steel through TMCP and its application, Iron \& Steel. 40 (2005) 368.

[13] Ministry of Metallurgical Industry of the People's Republic of China. GB/T 6478-86, Cole Heading Steel Technical Requirements [S]. Beijing: Metallurgical Industry Press,1986, 368(in chinese).

[14] Y.H. Seung, Y.S. Sang, L. Sunghak, Effects of cooling conditions on tensile and charpy impact properties of API X80 linepipe steels, Metall. Mater. Trans. A. 41 (2010): 329. 